\title{
Global NEST
}

\section{BIOSORPTION OF METHYLENE BLUE FROM AQUEOUS SOLUTIONS BY MODIFIED MESOPOROUS SIMAROUBA GLAUCA SEED SHELL POWDER}

\author{
JEYAGOWRI B. ${ }^{1{ }^{*}}$ \\ YAMUNA R.T. ${ }^{2}$
}

\author{
${ }^{1}$ Department of Chemistry \\ Hindusthan College of Engineering and Technology \\ Coimbatore - 641032, India \\ ${ }^{b}$ Department of Chemistry \\ Kalaignar Karunanidhi Institute of Technology \\ Coimbatore -641402, India
}

Received: $12 / 07 / 2015$

Accepted: 26/09/2015

Available online: 06/10/2015 *to whom all correspondence should be addressed: e-mail: gowrivasuphd2010@gmail.com

\section{ABSTRACT}

The present study investigates the ability of formaldehyde treated Simarouba glauca seed shell powder for removal of methylene blue (MB) from aqueous solutions. Batch adsorption studies were carried out under various experimental conditions such as agitation time, dye concentration, adsorbent dose and $\mathrm{pH}$. The adsorbent was characterized by Fourier Transform Infrared Spectroscopy (FTIR), Scanning Electron Microscopy (SEM), XRD, BET and CHNS analysis. The adsorption data were analysed using Langmuir, Freundlich, Temkin and Dubinin - Radushkevich isotherms. Equilibrium data fitted well to Langmuir isotherm with maximum adsorption capacity of $111.1 \mathrm{mg} \mathrm{g}^{-1}$. Adsorption kinetic data were verified using pseudo first order, pseudo second order and Intraparticle diffusion model. The kinetic data were found to fit well with pseudo second order model.

Keywords: Biosorption, Simarouba glauca seed shell, Methylene blue, Adsorption isotherm, Kinetic studies

\section{Introduction}

The textile wastewater containing dyes are highly colored and considered as one of the major source for the environmental concern. The discharge of colored wastewater with high amount of suspended solids and high COD causes significant problems such as increasing the toxicity and chemical oxygen demand. The colored wastewater also affects the photosynthetic activity of aquatic life by reduced penetration. Moreover, dyes are toxic, mutagenic or carcinogenic and disturb the ecosystem (Al-Anber et al., 2011; Garg et al., 2004; Bhattacharyya and Sharma, 2005; Hameed and Ahmad, 2009). Synthetic dyes have low biodegradability due to complex molecular structure and are too hard to eliminate under aquatic environment. Therefore, the treatment of wastewater containing synthetic dyes is necessary and very important. As synthetic dyes have low degradability, conventional biological methods in treating dye wastewater are not efficient. The physico - chemical treatment methods such as ion exchange, ultrafiltration, electrocoagulation, photo-oxidation, reverse osmosis, microwave oxidation etc., have their own significant disadvantages like incomplete removal,

Jeyagowri B. and Yamuna R.T. (2015), Biosorption of methylene blue from aqueous solutions by modified mesoporous Simarouba glauca seed shell powder, Global NEST Journal, 17(4), 701-715. 
high energy requirement and production of toxic sludge as waste products require proper disposal (Al-Anber et al., 2011; Hameed and Ahmad, 2009; Asgher and Bhatti, 2012).

Adsorption is one of the effective and economic techniques that have been successfully employed for treatment of textile wastewater. Although activated carbons have been recognized as effective commercial adsorbents for treating dye wastewaters, their high cost, limits their application. Biosorption technology has been found to be a cost effective and highly efficient method. The uses of biomass/ biomaterials in the treatment of wastewater are highly successful due to its low cost, high efficiency, regeneration of biosorbents and less chemical or biological sludge generation (Dogan et al., 2009). A number of low cost biosorbents such as spent tea leaves (Hameed, 2009), modified wheat straw (Zhang et al., 2011), peanut husk (Song et al., 2011), Citrus sinensis bagasse (Bhatti et al., 2012), Green pea peels (Dod et al.,2012), oil palm empty fruit bunch fibers (Sajab et al., 2013), pine saw dust (Witek-Krowiak, 2013), Cattail leaves (Guechi and Hamdaoui, 2013), egg shells (Podstawczyk et al., 2014), breadnut peel (Chieng et al.,2015) have been studied in the literature for their capacity to remove methylene blue from aqueous solutions.

Methylene Blue $(\mathrm{MB})$ is a thiazine (cationic) dye which has been widely used including coloring paper, temporary hair colorant, dyeing cottons, wools and coating for paper stock. Though MB is not strongly hazardous, its acute exposure cause increased heart rate, vomiting, shock, Heinz body formation, cyanosis, jaundice, quadriplegia and tissue necrosis in humans (Aksu et al., 2010).

Simarouba glauca, commonly known as paradise tree is an edible oil seed bearing tree well suited for warm, humid and tropical regions. This eco friendly tree with well developed root system and with evergreen dense canopy efficiently checks soil erosion, supports soil microbial life and improves ground water position. The seed contains about 50 - 60\% oil with 63\% unsaturated fatty acid among which $59.1 \%$ is oleic acid and is fit for human consumption. Many research studies are going on in efficient usage of biodiesel from Simarouba glauca seed oil (Devan and Mahalakshmi, 2009). The seed shell, a waste product from this eco friendly tree has been used for the present study for the removal of $\mathrm{MB}$ from aqueous solutions. The present study involves the potential utilization of formaldehyde treated Simarouba glauca seed shell in the removal of MB from aqueous solutions. The effect of $\mathrm{pH}$, initial dye concentration, adsorption isotherm and kinetic parameters for the biosorption were evaluated.

\section{Materials and methods}

\subsection{Materials}

Simarouba glauca seed shells were collected from Gujarat, India and the dye MB were purchased from SFCL Limited, New Delhi.

\subsection{Preparation of adsorbent - Steam Activated and Formaldehyde Treated Sorbent (SFTS)}

The seed shells were powdered and were steam activated in a stainless steel autoclave at a temperature of $121{ }^{\circ} \mathrm{C}$ for 40 minutes and then washed well with distilled water. The washed material was then treated with $1 \%$ formaldehyde in the ratio $1: 5$ and was heated in hot air oven at $50^{\circ} \mathrm{C}$ for 4 hours. The seed shell powder was filtered, washed again with distilled water to remove free formaldehyde and activated at $80^{\circ} \mathrm{C}$ in hot air oven for $24 \mathrm{hrs}$. The treated material (SFTS) was sieved for the particle size $75-150 \mu \mathrm{m}$ and stored in an air tight plastic container for further use.

\subsection{Characterization of adsorbent}

The adsorbent was characterized using FT-IR spectra and scanning electron microscopy (SEM, JSM-6390, JOEL). The infrared spectra of the sample were obtained using a Fourier transform infrared spectrometer (Shimadzu, model IRAffinity-1). The surface area, pore volume and average pore diameter were determined 
by nitrogen sorption at 77K (Micromeritics, ASAP 2010). The $X$ - ray diffractograms were obtained using PANalytical X'Pert PRO, PANalytical B.V., Almelo, The Netherlands. The surface morphological features of the sample were obtained using scanning electron microscopy. The elemental analysis of the sample was carried out using Elementar Vario EL III. The zero point of charge of the adsorbent was also determined.

\subsection{Adsorption experiments}

The adsorption experiments were carried out in a batch process of standard solutions of $\mathrm{MB}$. A stock solution of the dye MB (1000 $\left.\mathrm{mg} \mathrm{l}^{-1}\right)$ was prepared by dissolving $1 \mathrm{~g}$ of the dye in 1 litre of distilled water, which was diluted to desired concentration. Batch adsorption experiments were carried by adding $0.1 \mathrm{~g}$ of SFTS into 250 $\mathrm{ml}$ Erlenmeyer flasks containing $50 \mathrm{ml}$ of different initial concentrations (150, 200, 250 and $300 \mathrm{mg} \mathrm{l}^{-1}$ ) of MB solution. The flasks were agitated in a rotary shaker at room temperature until equilibrium was reached. After equilibration time, the adsorbents were separated by filtration and the concentration of $M B$ in the supernatant were determined at $\lambda \max 667 \mathrm{~nm}$ by Visible spectrophotometer (Shimadzu Visible Spectrophotometer UVmini-1240V) and the amount of dye adsorbed was calculated.

The effect of $\mathrm{pH}$ on the removal of MB by SFTS were carried out using $50 \mathrm{ml}$ of $200 \mathrm{mg} \mathrm{l}^{-1}$ of MB solution, agitated with $0.1 \mathrm{~g}$ of SFTS at initial $\mathrm{pH}$ values ranging from 2 to 11 . The initial $\mathrm{pH}$ was adjusted by using 0.1 $\mathrm{M} \mathrm{HCl}$ and $0.1 \mathrm{M} \mathrm{NaOH}$. The effect of adsorbent dose on the equilibrium uptake of $200 \mathrm{mg} \mathrm{I}^{-1}$ of MB was investigated using various adsorbent dosage between $0.05 \mathrm{~g}$ to $0.2 \mathrm{~g}$ respectively. All studies were carried out at equilibrium time of $60 \mathrm{~min}$ and at temperature $30 \pm 2{ }^{\circ} \mathrm{C}$.

\subsection{Desorption studies}

The dye loaded sorbents were prepared by agitating $0.2 \mathrm{~g}$ of adsorbent into $50 \mathrm{ml}$ of dye solution for $60 \mathrm{~min}$ on a rotary shaker. The dye loaded sorbent was separated out by filtration using Whatman Filter paper No.42 and filtrate was discarded. The dye loaded sorbent was given a gentle wash with distilled water to remove unadsorbed $\mathrm{MB}$ if present. The dye loaded adsorbent was agitated with desorbing mediums such as distilled water, $0.1 \mathrm{M} \mathrm{HCl}$ and $0.1 \mathrm{M} \mathrm{CH}_{3} \mathrm{COOH}$ for $60 \mathrm{~min}$ (Fernandez et al., 2010). The desorbed $\mathrm{MB}$ in the solution was separated and analyzed as before. The percentage of desorption was calculated.

\section{Results and discussion}

\subsection{Characterization of adsorbent}

The FT IR spectra of adsorbent SFTS were taken before and after dye adsorption (Fig. 1).

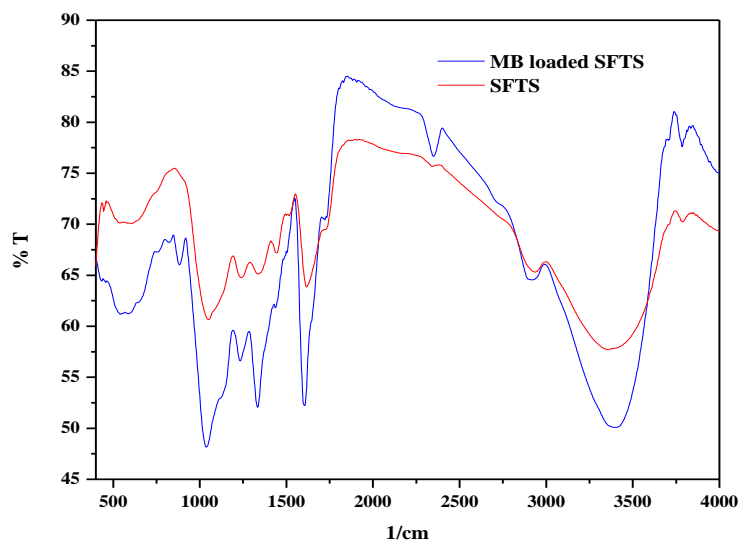

Figure 1. FT-IR spectrum of SFTS before and after adsorption 
The broad and intense band at $3356 \mathrm{~cm}^{-1}$ corresponds to $\mathrm{O}-\mathrm{H}$ stretching vibrations. The band at $2935 \mathrm{~cm}^{-1}$ represents symmetric or asymmetric $\mathrm{C}-\mathrm{H}$ stretching vibration of aliphatic acids. The bands at $1616 \mathrm{~cm}^{-1}$ and $1516 \mathrm{~cm}^{-1}$ reveal the aromatic $\mathrm{C}-\mathrm{C}$ stretching in phenyl ring of lignin. The absorption band at $1450 \mathrm{~cm}^{-1}$ is assigned to methoxy group of lignin (Anoop Krishnan and Haridas, 2008; Benyoucef and Amrani, 2011). A weak absorption band at $1722 \mathrm{~cm}^{-1}$ corresponds to $\mathrm{C}=\mathrm{O}$ stretching of $-\mathrm{COOH}$ group. The FT IR spectrum well indicates the presence of hydroxyl and carbonyl groups in SFTS. The disappearance of peak at $1722 \mathrm{~cm}^{-1}$ and shifting of peaks confirms the involvement of functional groups in SFTS in adsorption process. The X-Ray diffractogram of SFTS (Fig. 2a) with sharp peaks confirms the crystalline nature of the adsorbent. The disappearance of these sharp peaks in X-Ray diffractogram of dye loaded adsorbent (Fig. 2b) confirms the effective adsorption of dye molecules onto adsorbent surface. The elemental analysis of SFTS was also done and the composition is shown in Table 1.

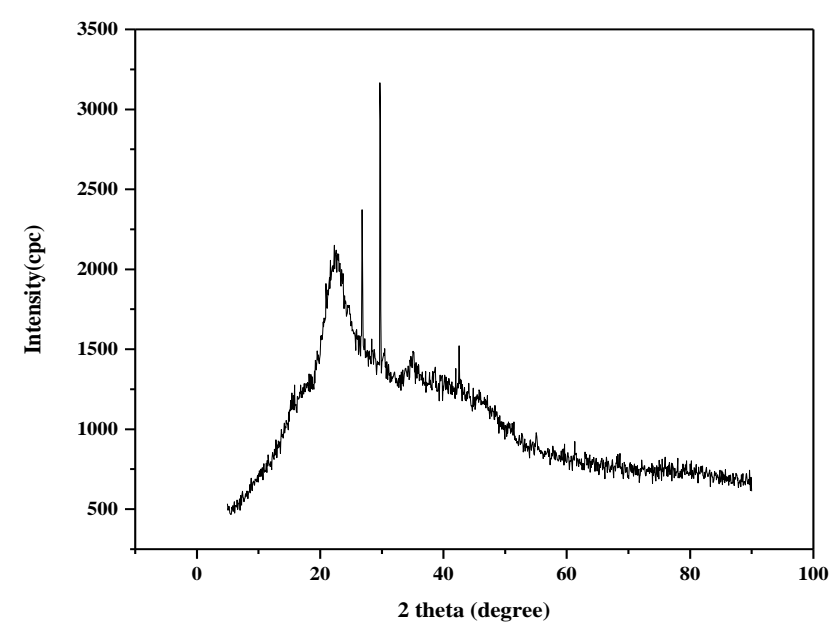

(a)

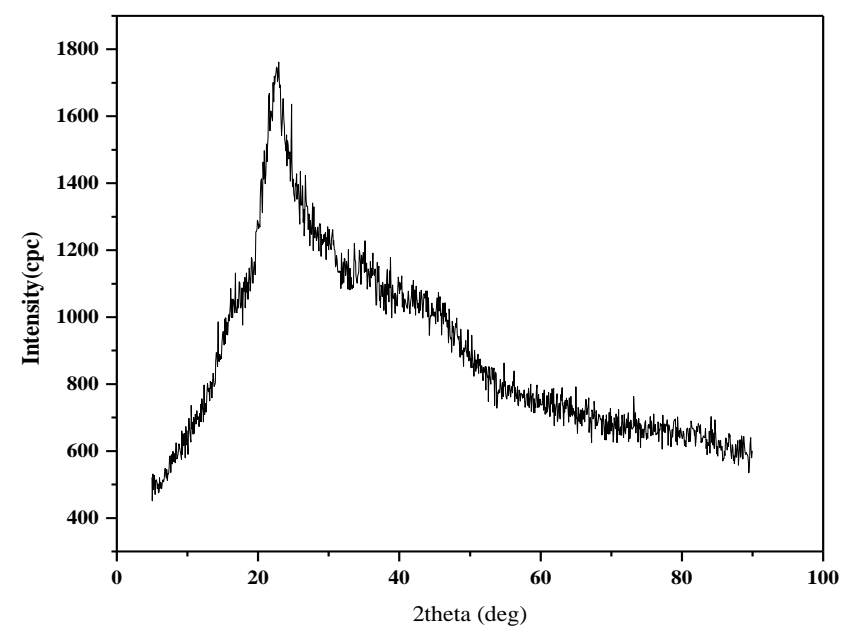

(b)

Figure 2. X- ray diffraction pattern of SFTS a) before adsorption and b) after adsorption 
Table 1. Physicochemical characterization of SFTS

\begin{tabular}{c|c}
\hline Parameters & Values \\
\hline BET surface area & $1.8704 \mathrm{~m}^{2} \mathrm{~g}^{-1}$ \\
\hline Total pore volume & $0.003948 \mathrm{~cm}^{3} \mathrm{~g}^{-1}$ \\
\hline Average pore diameter & $8.4422 \mathrm{~nm}$ \\
\hline Zero point of charge $\left(\mathrm{pH}_{\mathrm{zpc}}\right)$ & 3.8 \\
\hline $\mathrm{C} \%$ & 52.21 \\
\hline $\mathrm{H} \%$ & 7.07 \\
\hline $\mathrm{N} \%$ & 1.32 \\
\hline $\mathrm{S} \%$ & 0.32 \\
\hline
\end{tabular}

The SEM micrographs of SFTS before and after adsorption are shown in Fig.3.

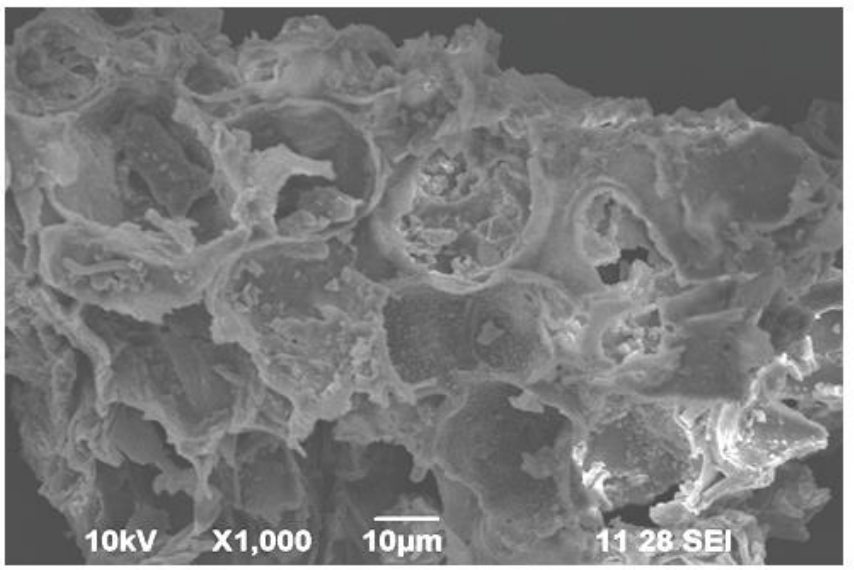

(a)

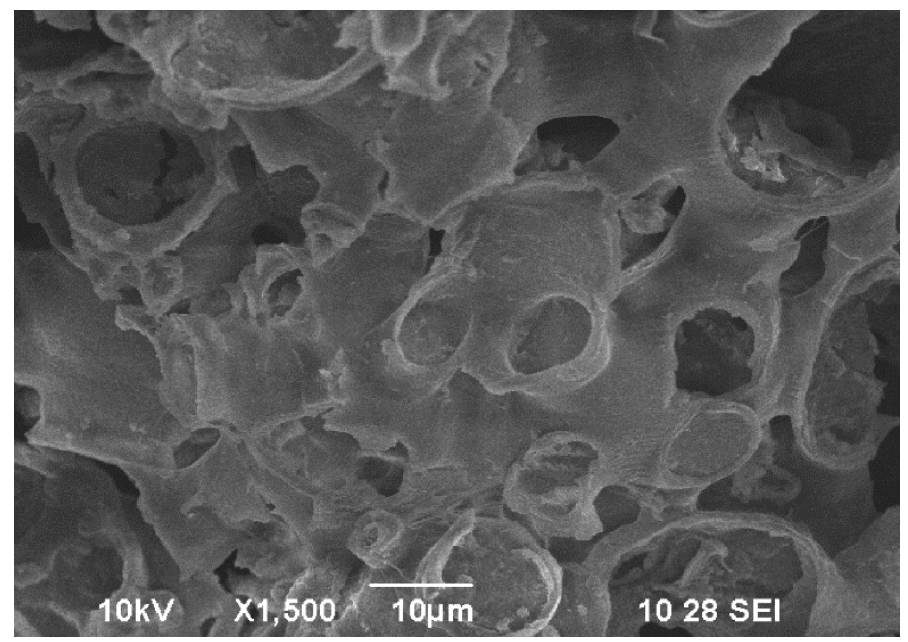

(b)

Figure 3. SEM image of SFTS a) before adsorption and b) after adsorption 
The availability of pores and rough surface of SFTS are clearly seen in Fig. 3a. The SEM micrograph of dye loaded SFTS clearly shows the coverage of pores and the surface by adsorption of dye molecules on to the adsorbent surface. The BET surface area, total pore volume and average pore diameter of SFTS were given in Table 1. The pore size distribution of SFTS is shown in Fig. 4. It is seen from the figure that most pores of SFTS are in the mesoporous range (diameter $2-50 \mathrm{~nm}$ ) (Wang et al., 2010). The average pore diameter of SFTS (Table 1) confirms the mesoporous nature of SFTS.

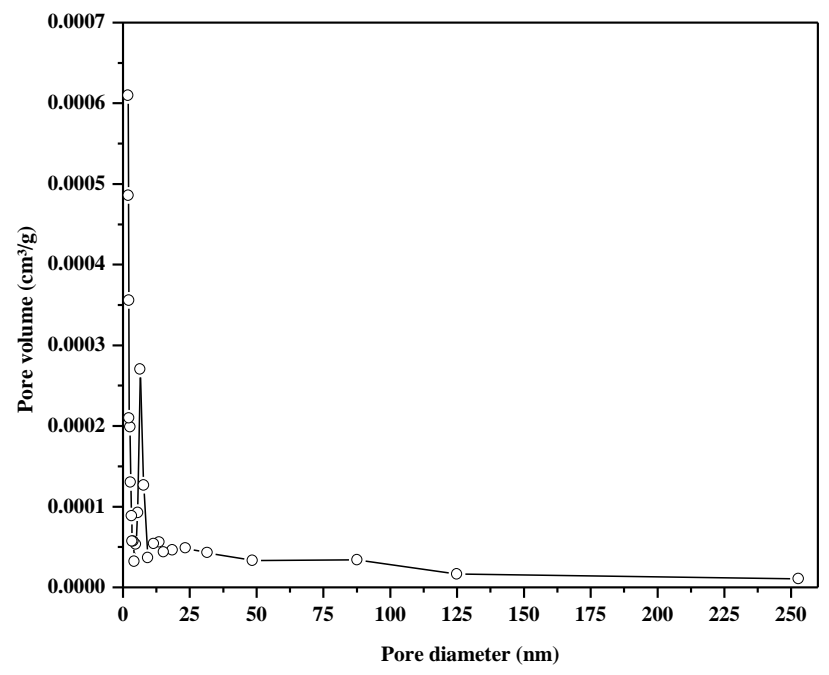

Figure 4. Pore size distribution of SFTS

\subsection{Effect of initial dye concentration and contact time}

The adsorption experiments were carried out for different contact time at initial dye concentration (150, 200,250 and $300 \mathrm{mg} \mathrm{l}^{-1}$ ) with adsorbent dose of $0.1 \mathrm{~g}$ at natural pH. Fig. 5 shows the effect of varying dye concentrations against the amount of $\mathrm{MB}$ adsorbed. The adsorption increases from 63 to $97 \mathrm{mg} \mathrm{g}^{-1}$ with increase in initial $\mathrm{MB}$ concentration from 150 to $300 \mathrm{mg} \mathrm{l}^{-1}$. This is due to the fact that with increase in concentration of $\mathrm{MB}$, availability of $\mathrm{MB}$ at adsorbent interface also increases, thus increasing the amount of adsorption. The extent of adsorption reaches a saturated limit when the active sites in the surface of adsorbent are fully covered.

Fig.5 also represents the effect of contact time on the initial concentration of MB. The uptake of MB is rapid at the initial stages and thereafter it becomes near to the equilibrium. It can be explained based on the fact that a large number of vacant surface sites are available for adsorption during the initial stage and after a period of time, the remaining vacant surface sites are difficult to be occupied due to repulsive forces between solute molecules on solid and bulk phases (Gusmao et al., 2012). Fig.5 clearly shows the equilibrium time of 60 min for removal of MB by SFTS. The plots are single, smooth and continuous leading to saturation, suggesting the possibility of formation of monolayer coverage of the dye (Yamuna and Namasivayam, 1993).

\subsection{Effect of $\mathrm{pH}$}

The $\mathrm{pH}$ of the aqueous solution is an important parameter in the adsorption of dyes on the biosorbents. The influence of the initial $\mathrm{pH}$ of solution on the adsorption of MB onto SFTS was studied in the $\mathrm{pH}$ range of 2 11(Fig.6). From the Fig. 6, it is clear that the adsorption capacity increases from 37 to $75 \mathrm{mg} \mathrm{g}^{-1}$ with increase in $\mathrm{pH} 2$ to 8 , and then remains constant with increase in further $\mathrm{pH}$ of the solution. 


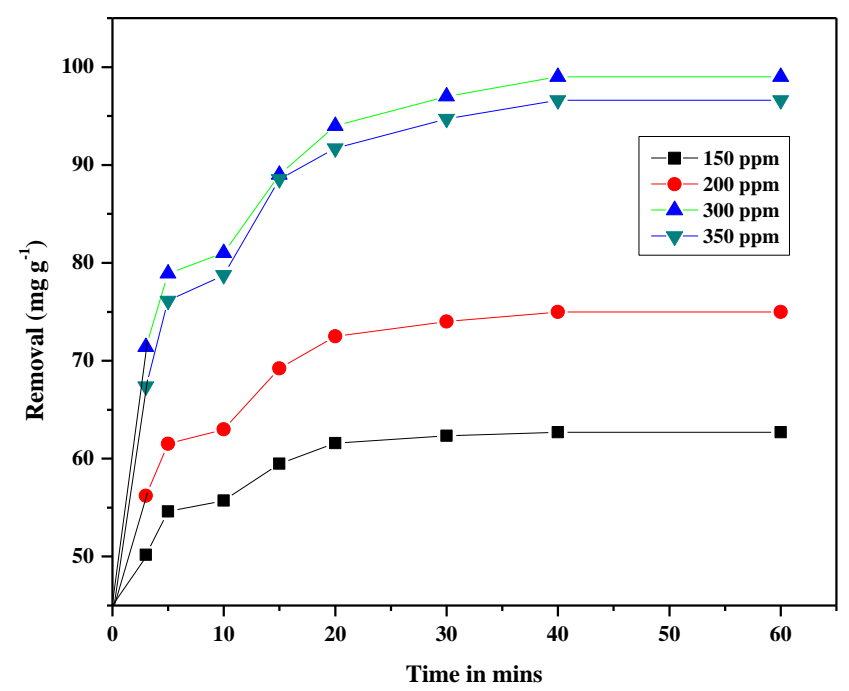

Figure 5. Effect of contact time on adsorption of MB onto SFTS (adsorbent dose $=0.1 \mathrm{~g} / 50 \mathrm{ml}$ )

The influence of $\mathrm{pH}$ on the adsorption of $\mathrm{MB}$ can be explained on the basis of point zero charge $\left(\mathrm{pH}_{2 \mathrm{pc}}\right)$ of the adsorbent. The $\mathrm{pH}_{\mathrm{zpc}}$ of SFTS was determined to be at $\mathrm{pH}$ 3.8. The surface of the adsorbent is positively charged at the $\mathrm{pH}$ lower than the $\mathrm{pH}_{\mathrm{zpc}}$, a high concentration of $\mathrm{H}^{+}$ions at acidic solution compete with dye cations on the surface of adsorbent, resulting in the suppression of dye adsorption at low pH. At pH higher than $\mathrm{pH}_{\mathrm{zpc}}$, the surface of the adsorbent becomes negatively charged and there exists a strong electrostatic attraction of dye cations with the adsorbent leading to the increased adsorption. Similar effect was observed in the adsorption of MB dye from aqueous solutions by succinylated sugarcane bagasse (Gusmao et al., 2012), tea waste (Uddin et al., 2009), EDTAD modified Bagasse (Xing et al., 2010).

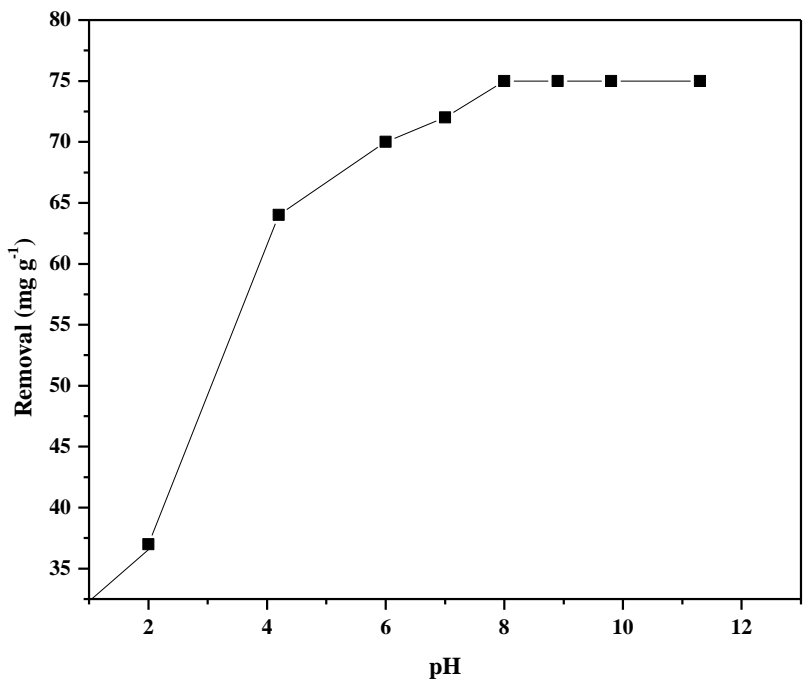

Figure 6. Effect of $\mathrm{pH}$ on adsorption of MB onto SFTS (adsorbent dose $=0.1 \mathrm{~g} / 50 \mathrm{ml}, \mathrm{C}=200 \mathrm{mg} \mathrm{l}^{-1}, \mathrm{t}=60 \mathrm{~min}$ ) 


\subsection{Effect of adsorbent dose}

The adsorption of MB onto SFTS as a function of adsorbent dose is shown in Fig. 7. It is clear from the figure that the dye removal increases from 68 to $90 \%$ with increase in adsorbent dose from 0.05 to 0.2 per $50 \mathrm{ml}$ of the dye solution. The reason for the increased adsorption may be attributed to greater surface area and large number of vacant sites thus favoring more adsorption.

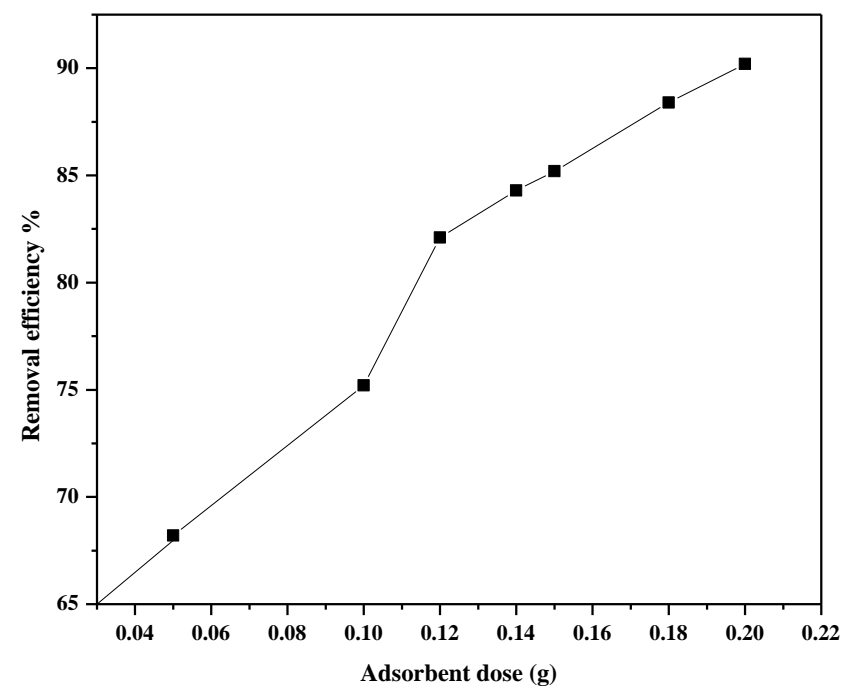

Figure 7. Effect of adsorbent dose on adsorption of MB onto SFTS $\left(\mathrm{V}=50 \mathrm{ml}\right.$, initial concentration $=200 \mathrm{mg} \mathrm{l}^{-1}, \mathrm{t}=60 \mathrm{~min}$ )

\subsection{Isotherm analysis}

The adsorption isotherms are used to indicate the distribution of molecules between the liquid phase and the solid phase when the adsorption process reaches an equilibrium state. The amount of dye adsorbed at equilibrium reflects the maximum adsorption capacity of the adsorbent under operating conditions. The adsorption isotherms provide fundamental physiochemical data for evaluating the applicability of the adsorption process as a unit operation. The Langmuir, Freundlich, Temkin and D-R isotherm models were used to describe the data derived from the adsorption of MB by SFTS.

\subsubsection{Langmuir adsorption isotherm}

The Langmuir adsorption isotherm is based on the assumption that maximum adsorption corresponds to a saturated monolayer of solute molecules on the adsorbent surface, with no lateral interactions between sorbed molecules. The linear form of Langmuir adsorption isotherm is expressed as (Hameed et al., 2008a)

$C_{e} / q_{e}=1 / Q_{0} b+C_{e} / Q_{0}$

where $\mathrm{q}_{\mathrm{e}}\left(\mathrm{mg} \mathrm{g}^{-1}\right)$ and $\mathrm{C}_{\mathrm{e}}\left(\mathrm{mg} \mathrm{l}^{-1}\right)$ is amount of dye adsorbed per unit mass of adsorbent per unit mass of adsorbent and equilibrium concentration of dye. $Q_{o}$ and $b$ are the Langmuir constants related to adsorption capacity and rate of adsorption respectively. The linear plots of $C_{e} / q_{e} v s C_{e}$ (Fig. 8) shows that the adsorption obeys Langmuir isotherm and indicates the monolayer coverage of MB molecules at the outer surface of SFTS. The Langmuir constants $Q_{0}$ and $b$ were determined from the slope and intercept of the plot and are presented in Table 2. 


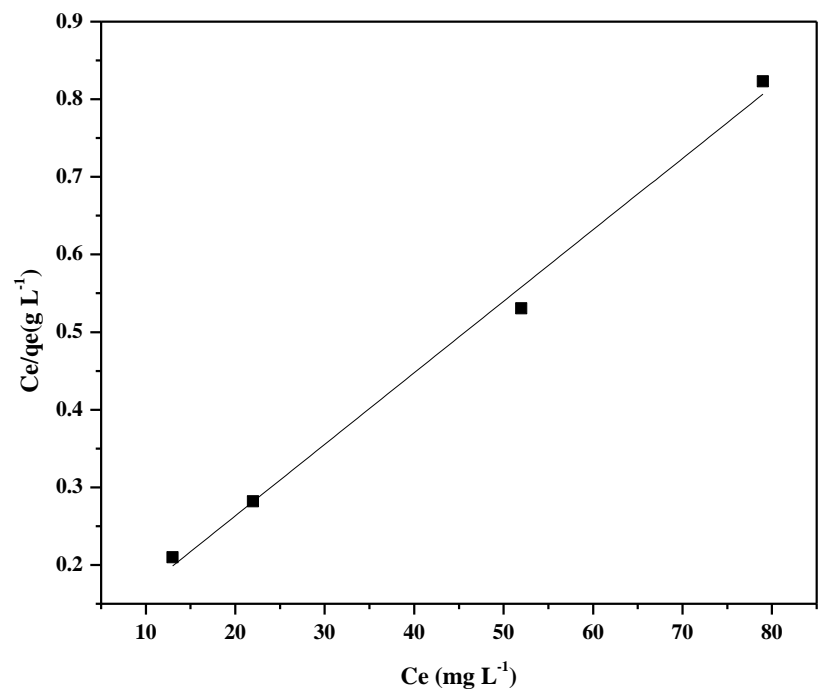

Figure 8. Langmuir adsorption isotherm for the adsorption of MB onto SFTS (adsorbent dose $=0.1 \mathrm{~g} / 50 \mathrm{ml}$, initial concentration $=200 \mathrm{mg} \mathrm{l}^{-1}, \mathrm{t}=60 \mathrm{~min}$ )

The essential characteristics of Langmuir isotherm can be expressed in terms of a dimensionless equilibrium parameter $\left(R_{L}\right)$ (Hameed et al., 2008a) by the following equation

$\mathrm{R}_{\mathrm{L}}=1 /\left(1+\mathrm{b} \mathrm{C}_{0}\right)$

where $b\left(\mathrm{~L} \mathrm{mg}^{-1}\right)$ is the Langmuir constant and $C_{0}\left(\mathrm{mg} \mathrm{l}^{-1}\right)$ is the highest initial concentration of dye. The $R_{\mathrm{L}}$ value indicates the shape of isotherm to be either unfavorable $\left(R_{L}>1\right)$, linear $\left(R_{L}=1\right)$, favorable $\left(0<R_{L}<1\right)$ or irreversible $\left(R_{L}=0\right)$. $R_{L}$ values between 0 and 1 indicate favorable adsorption. The $R_{L}$ value for the present study was found to be 0.026 indicating the favorable adsorption of MB onto SFTS. The comparison of adsorption capacities $\left(Q_{0}\right)$ of various adsorbents for $M B$ is presented in Table 3.

Table 2 Isotherm parameters for adsorption of MB onto SFTS

\begin{tabular}{c|c|c}
\hline Isotherm & Parameters & Values \\
\hline \multirow{4}{*}{ Langmuir } & $\mathrm{Q}_{0}\left(\mathrm{mg} \mathrm{g}^{-1}\right)$ & 111.1 \\
\cline { 2 - 3 } & $\mathrm{b}\left(\mathrm{I}^{-1} \mathrm{mg}^{-1}\right)$ & 0.105 \\
\cline { 2 - 3 } & $\mathrm{R}^{2}$ & 0.993 \\
\hline \multirow{4}{*}{ Freundlich } & $\mathrm{K}_{\mathrm{F}}\left(\mathrm{I} \mathrm{g}^{-1}\right)$ & 33.35 \\
\cline { 2 - 3 } & $\mathrm{n}$ & 3.91 \\
\cline { 2 - 3 } & $\mathrm{R}^{2}$ & 0.937 \\
\hline \multirow{3}{*}{ Temkin } & $\mathrm{A}^{(}\left(\mathrm{g} \mathrm{g}^{-1}\right)$ & 1.775 \\
\cline { 2 - 3 } & $\mathrm{B}\left(\mathrm{KJ} \mathrm{mol}^{-1}\right)$ & 20.44 \\
\cline { 2 - 3 } & $\mathrm{R}^{2}$ & 0.929 \\
\hline \multirow{3}{*}{$\mathrm{D}-\mathrm{R}$} & $\mathrm{Q}_{\mathrm{m}\left(\mathrm{mol} \mathrm{g}^{-1}\right)}$ & 94.63 \\
\cline { 2 - 3 } & $\mathrm{E}\left(\mathrm{KJ} \mathrm{mol}^{-1}\right)$ & 0.222 \\
\cline { 2 - 3 } & $\mathrm{R}^{2}$ & 0.862 \\
\hline
\end{tabular}


Table 3 Comparison of adsorption capacities of various low cost adsorbents for MB

\begin{tabular}{lcc}
\hline \multicolumn{1}{c}{ Adsorbents } & $\mathbf{Q}_{\mathbf{0}}\left(\mathbf{m g ~ g}^{-\mathbf{1}}\right)$ & References \\
\hline Simarouba glauca seed shell powder & 111.1 & This study \\
\hline Defatted Jojoba & 185 & Al-Anber et al., 2011 \\
\hline Silkworm exuviae & 25.530 & Chen et al., 2011 \\
\hline Modified wheat straw & 257.8 & Zhang et al., 2011 \\
\hline Citrus sinensis bagasse & 112.36 & Bhatti et al., 2012 \\
\hline Green Pea Peels & 163.94 & Dod et al., 2012 \\
\hline Peanut husk & $72.13 \pm 3.03$ & Song et al., 2011 \\
\hline Banana stalk waste & 243.902 & Hameed et al., 2008a \\
\hline Garlic peel & 82.64 & Hameed and Ahmad, 2009 \\
\hline Sugarcane bagasse (SB) & 27.29 & Xing et al., 2010 \\
\hline EDTAD-SB & 115.3 & Xing et al., 2010 \\
\hline Palm kernel fiber & 95.4 & El-Sayed, 2011 \\
\hline Rice husk & 8.07 & Chen Shih, 2012 \\
\hline Coconut bunch waste & 70.92 & Hameed et al., 2008b \\
\hline Papaya seeds & 555.557 & Hameed, 2009 \\
\hline Rejected Tea & 147 & Nasuha et al., 2010 \\
\hline
\end{tabular}

\subsubsection{Freundlich adsorption isotherm}

The Freundlich isotherm is regarded as an empirical isotherm which indicates the surface heterogeneity of the adsorbent. The linear form of isotherm is expressed as (Senturk et al., 2010)

$\ln \mathrm{q}_{\mathrm{e}}=\ln \mathrm{K}_{\mathrm{f}}+1 / \mathrm{n} \ln \mathrm{C}_{\mathrm{e}}$

where $K_{f}$ and $n$ are freundlich adsorption constants related to adsorption capacity and sorption intensity. The value of $\mathrm{n}$ varies with the heterogeneity of sorbent and gives an idea for the favorability of sorption process. The value of $\mathrm{n}$ less than 10 and higher than unity is favorable for adsorption (Senturk et al., 2010). The values of Freundlich constants $\mathrm{K}_{\mathrm{f}}$ and $1 / \mathrm{n}$ were obtained from the linear plot of $\ln \mathrm{q}_{\mathrm{e}} \mathrm{vs} \ln \mathrm{C}_{\mathrm{e}}$ and presented in Table 2. The Freundlich constant $1 / \mathrm{n}$ was smaller than unity indicates the favorable adsorption of MB onto SFTS.

\subsubsection{Temkin adsorption isotherm}

Temkin isotherm is based on the assumption that the heat of adsorption of all the molecules in the layer would decrease linearly with coverage due to adsorbate/adsorbent interactions. The linear form of Temkin isotherm is commonly represented as (Anandkumar and Mandal, 2011)

$\mathrm{q}_{\mathrm{e}}=\mathrm{B} \ln \mathrm{A}+\mathrm{B} \ln \mathrm{C}_{\mathrm{e}}$

where $R T / b=B, R$ is the gas constant $\left(8.314 \mathrm{~J}^{-1} \mathrm{~mol}^{-1} \mathrm{~K}^{-1}\right)$ and $T(K)$ is the absolute temperature. The constant $B$ is related to the heat of adsorption and $A$ is the equilibrium constant $\left(\mathrm{min}^{-1}\right)$ corresponding to the binding energy. The linear plot of $\mathrm{q}_{\mathrm{e}} \mathrm{vs} \ln \mathrm{C}_{\mathrm{e}}$ enables the determination of constants $\mathrm{A}$ and $\mathrm{B}$. The values of parameters are presented in Table 2.

\subsubsection{Dubinin - Radushkevich (D-R) isotherm}

$D-R$ isotherm assumes that there is no homogeneous surface or constant biosorption potential. $D-R$ isotherm was applied to characterize the process of adsorption and evaluate the type of interaction between dye and the adsorbent. The linear form of D-R isotherm is represented as (El Bakouri et al., 2009)

$\ln Q_{e}=\ln Q_{m}-\beta \varepsilon^{2}$ 
where $Q_{m}$ is the maximum adsorption capacity $\left(\mathrm{mg} \mathrm{g}^{-1}\right), \beta$ is $D-R$ isotherm constant and $\varepsilon$ is the Polanyi potential. The constants $\beta\left(\mathrm{mol}^{2} \mathrm{KJ}^{-2}\right)$ and $Q_{m}\left(\mathrm{mg} \mathrm{g}^{-1}\right)$ can be calculated from the slope and intercept of the plot $\ln q_{\mathrm{e}} \mathrm{vs} \varepsilon^{2}$ and are presented in Table 2. $\varepsilon$, the Polanyi potential represents the work required to remove a molecule from its location, can be calculated as follows

$\varepsilon=R T \ln \left(1+1 / C_{e}\right)$

The mean free energy of adsorption $(E)$ is the free energy when one mole of ion transferred from infinity in solution to the surface of the sorbent. $E$ is calculated as follows

$E=(-2 \beta)^{1 / 2}$

The value of $E$ would give information about the nature of adsorption as physisorption or chemisorption. The adsorption process would be physisorption when $E$ lies between 1 and $8 \mathrm{KJ} \mathrm{mol}^{-1}$, it would be chemisorption when $\mathrm{E}$ is higher than $8 \mathrm{KJ} \mathrm{mol}^{-1}$. D-R isotherm parameters are presented in Table 2 . The maximum adsorption capacity $Q_{m}$ obtained using D-R isotherm for adsorption of MB onto SFTS is $94.63 \mathrm{~mol} \mathrm{~g}^{-1}$. The value of $E$ calculated is $0.22 \mathrm{KJ} \mathrm{mol}^{-1}$ indicates the physical adsorption of MB onto SFTS.

\subsection{Kinetic studies}

The adsorption kinetic studies were used to determine the adsorption behavior such as the adsorption type, rate and the capacity of the adsorption of the system (Malekbala et al., 2012). In order to investigate the adsorption behavior, three kinetic models pseudo first order, second order and intraparticle diffusion models were used.

\subsubsection{Pseudo first order kinetic model}

The pseudo first order model was expressed as (Malekbala et al., 2012)

$\log \left(q_{e}-q_{t}\right)=\log q_{e}-\left(K_{1} t\right) / 2.303$

The values of $K_{1}$ and $q_{e}{ }^{\text {cal }}$ can be obtained from the slope and intercept of the linear plot of log $\left(q_{e}-q_{t}\right) v s t$ and represented in Table 4. The correlation coefficient is low and $\mathrm{q}_{\mathrm{e}}{ }^{\mathrm{cal}}$ value did not show good agreement with the experimental one. This suggests that adsorption kinetics of MB on SFTS does not follow first order kinetics.

\subsubsection{Pseudo second order kinetic model}

The pseudo second order model is expressed as (Malekbala et al., 2012)

$t / q_{t}=1 / K_{2} q_{e}^{2}+t / q_{e}$

where $\mathrm{K}_{2}$ is the rate constant of adsorption $\left(\mathrm{g} \mathrm{mg}^{-1} \mathrm{~min}^{-1}\right), \mathrm{q}_{\mathrm{e}}$ and $\mathrm{q}_{\mathrm{t}}$ are amount of dye adsorbed $\left(\mathrm{mg} \mathrm{g}^{-1}\right)$ at equilibrium and time $t(\mathrm{~min})$. The values of $K_{2}$ and $q_{e}{ }^{\text {cal }}$ were calculated from the intercept $\left(1 / K_{2} q_{e}{ }^{2}\right)$ and slope $\left(1 / q_{e}\right)$ of the plot t/qt vs $t$ (Fig. 9) respectively and presented in Table 4. It can be seen from Table 4, there is an agreement between $\mathrm{q}^{\text {exp }}$ and $\mathrm{q}_{\mathrm{e}}^{\text {cal }}$ for the pseudo second order model. The higher correlation coefficient also suggests the applicability of pseudo second order model for adsorption of MB on SFTS.

\subsubsection{Intraparticle diffusion studies}

Adsorption takes place in multisteps involving the transfer of solute from bulk of solution to surface of adsorbent. Intraparticle diffusion plays an important role in the extent of adsorption (Gupta et al., 2012) and can be expressed as

$\mathrm{q}_{\mathrm{t}}=\mathrm{K}_{\mathrm{id}} \mathrm{t}^{0.5}+\mathrm{C}$ 
Where $\mathrm{K}_{\text {id }}$ is intraparticle diffusion constant $\left(\mathrm{mg} \mathrm{g}^{-1} \mathrm{~min}^{0.5}\right)$ and $\mathrm{C}$ is the intercept $\left(\mathrm{mg} \mathrm{g}^{-1}\right)$. The value of $\mathrm{C}$ gives an idea about the thickness of boundary layer, the layer the intercept greater the boundary layer effect. The value of $K_{\text {id }}$ and $C$ can be obtained from the linear plot of $\mathrm{q}_{\mathrm{t}} \mathrm{vs} \mathrm{t}^{0.5}$ (Fig. 10) and listed in Table 4.

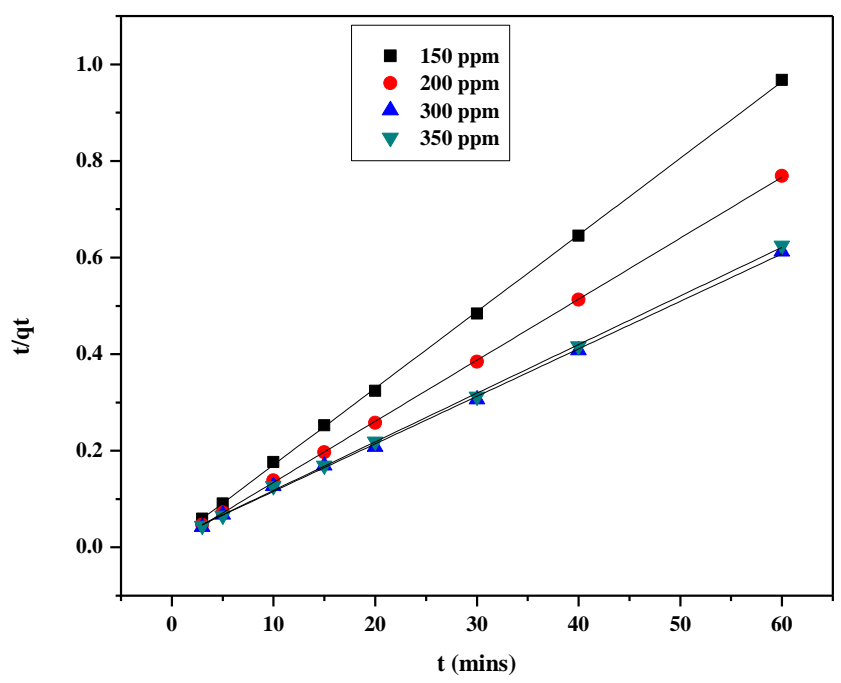

Figure 9. Pseudo second order plots for the adsorption of MG onto SFTS (adsorbent dose $=0.1 \mathrm{~g} / 50 \mathrm{~mL}$, initial concentration $=300 \mathrm{mg} \mathrm{l}^{-1}, \mathrm{t}=60 \mathrm{~min}$ )

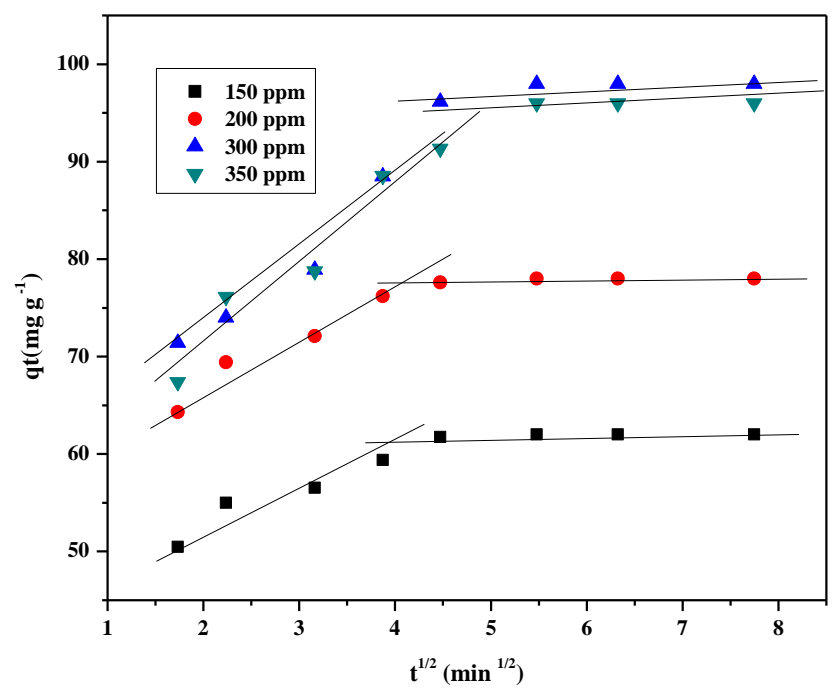

Figure 10. Intra particle diffusion plots for the adsorption of MB onto SFTS

The linear plot of $\mathrm{q}_{\mathrm{t}} \mathrm{vs} \mathrm{t}^{0.5}$ suggests that intraparticle diffusion might have a significant role in the adsorption of MB on SFTS. Since the linear plot did not pass through origin, it also suggests that although intraparticle diffusion was involved in adsorption process, it was not only the sole rate controlling step. It is clear from the Fig.10 that the adsorption processes involve more than one kinetic stage. The first linear portion was due to adsorption of dye molecules on to the adsorbent surface indicating boundary layer effect and the second linear portion is due to intra particle diffusion (Gupta et al., 2012; Dogan et al., 2009). 
Table 4. Kinetic parameters for adsorption of MB onto SFTS

\begin{tabular}{|c|c|c|c|c|c|c|c|c|c|}
\hline \multirow{2}{*}{$\begin{array}{l}\text { Concentration } \\
\mathrm{MG}\left(\mathrm{mg} \mathrm{l}^{-1}\right)\end{array}$} & \multirow{2}{*}{$\begin{array}{c}\mathrm{q}^{\mathrm{exp}} \\
\left(\mathrm{mg} \mathrm{g}^{-1}\right)\end{array}$} & \multicolumn{3}{|c|}{ Pseudo first order } & \multicolumn{3}{|c|}{ Pseudo second order } & \multicolumn{2}{|c|}{ Intraparticle diffusion } \\
\hline & & $\begin{array}{c}\mathrm{qe}^{\mathrm{cal}} \\
\left(\mathrm{mg} \mathrm{g}^{-1}\right)\end{array}$ & $\begin{array}{c}\mathrm{K}_{1} \\
\left(\mathrm{~min}^{-1}\right)\end{array}$ & $\mathrm{R}^{2}$ & $\begin{array}{c}\mathrm{q}^{\mathrm{cal}} \\
\left(\mathrm{mg} \mathrm{g}^{-1}\right)\end{array}$ & $\begin{array}{c}\mathrm{K}_{2} \\
\left(\mathrm{~g} \mathrm{mg}^{-1} \mathrm{~min}^{-1}\right)\end{array}$ & $\mathrm{R}^{2}$ & $\begin{array}{c}\mathrm{K}_{\mathrm{id}} \\
\left(\mathrm{mg} \mathrm{g}^{-1} \mathrm{~min}^{-1 / 2}\right)\end{array}$ & $\mathrm{R}^{2}$ \\
\hline 150 & 62.7 & 11.38 & 0.069 & 0.634 & 66.66 & 0.014 & 0.999 & 2.025 & 0.798 \\
\hline 200 & 75.4 & 27.86 & 0.106 & 0.979 & 83.33 & 0.075 & 0.999 & 3.279 & 0.848 \\
\hline 300 & 98.7 & 38.82 & 0.099 & 0.979 & 111.1 & 0.0047 & 0.999 & 4.666 & 0.873 \\
\hline 450 & 96.6 & 38.99 & 0.099 & 0.985 & 100.0 & 0.0055 & 0.999 & 4.866 & 0.840 \\
\hline
\end{tabular}

\subsection{Desorption studies}

Desorption studies helps to clarify the mechanism of adsorption process. If the dye adsorbed can be desorbed by water, a weak interaction exists between dye molecules and the adsorbent. If the strong acid such as $\mathrm{HCl}$ can desorb the dye, interaction would be of ion exchange. The adsorption process might be chemisorption if the dye adsorbed can be desorbed by weak acid $\mathrm{CH}_{3} \mathrm{COOH}$ (Chen et al., 2011). In the present study, desorption of $\mathrm{MB}$ was found to be $0.32 \%, 32.1 \%$ and $22 \%$ for $\mathrm{H}_{2} \mathrm{O}, \mathrm{HCl}$ and $\mathrm{CH}_{3} \mathrm{COOH}$. The higher desorption in $\mathrm{HCl}$ compared to $\mathrm{H}_{2} \mathrm{O}$ and $\mathrm{CH}_{3} \mathrm{COOH}$ suggests the physical adsorption (ion exchange) of MB onto SFTS. Similar behavior has been observed in Silkworm exuviae (Chen et al., 2011), wheat straw materials (Zhang et al., 2011) and citric acid modified kenaf fibres (Sajab et al., 2011).

\section{Conclusion}

The present study shows that the Simarouba glauca seed shell powder can be used as an effective adsorbent for removal of methylene blue from aqueous solutions. The equilibrium data showed best fit for Langmuir isotherm with maximum adsorption capacity of $111.1 \mathrm{mg} \mathrm{g}^{-1}$. The optimum $\mathrm{pH}$ was found to be 8 . The kinetic data were found to follow pseudo second order model and the adsorption of methylene blue was controlled by boundary layer effect and intraparticle diffusion. Desorption studies shows the predominance of physical adsorption of methylene blue onto the adsorbent surface.

\section{References}

Aksu Z., Ertugrul S. and Donmez G. (2010), Methylene Blue biosorption by Rhizopus arrhizus: Effect of SDS (sodium dodecyl sulfate) surfactant on biosorption properties, Chem. Eng. J., 158, 474-481.

Al-Anber Z.A., Al-Anber M.A., Matouq M., Al-Ayed O. and Omari N.M. (2011), Defatted Jojoba for the removal of methylene blue from aqueous solution: Thermodynamic and kinetic studies, Desalination, 276, 169-174.

Anandkumar J. and Mandal B. (2011), Adsorption of chromium (VI) and Rhodamine B by surface modified tannery waste: Kinetic, mechanistic and thermodynamic studies, J. Hazrd. Mater., 186, 1088-1096.

Anoop Krishnan K. and Haridas A. (2008), Removal of phosphate from aqueous solutions and sewage using natural and surface modified coir pith, J. Hazrd. Mater., 152, 527-535.

Asgher M. and Bhatti H.N. (2012), Evaluation of thermodynamics and effect of chemical treatments on sorption potential of citrus waste biomass for removal of anionic dyes from aqueous solutions, Ecol. Eng., 38, 79-85.

Benyoucef S. and Amrani M. (2011), Adsorption of phosphate ions onto low cost Aleppo pine adsorbent, Desalination, 275, 231-236.

Bhattacharyya K.G. and Sharma A. (2005), Kinetics and thermodynamics of Methylene Blue adsorption on Neem (Azadirachta indica) leaf powder, Dyes and Pigments, 65, 51-59.

Bhatti H.N., Akhtar N. and Saleem N. (2012), Adsorptive Removal of Methylene Blue by Low-Cost Citrus sinensis Bagasse: Equilibrium, Kinetic and Thermodynamic Characterization, Arab. J. Chem., 37, 9-18. 
Chen H., Zhao J. and Dai G. (2011), Silkworm exuviae-A new non-conventional and low-cost adsorbent for removal of methylene blue from aqueous solutions, J.Hazard. Mater., 186, 1320-1327.

Chieng H.I., Lim L.B.L. and Priyantha N. (2015), Enhancing adsorption capacity of toxic malachite green dye through chemically modified breadnut peel: equilibrium, thermodynamics, kinetics and regeneration studies, Environ Technol., 36(1), 86-97.

Devan P.K. and Mahalakshmi N.V. (2009), Utilization of unattended methyl ester of paradise oil as fuel in diesel engine, Fuel, 88 1828-1833.

Dogan M., Abak H. and Alkan M. (2009), Adsorption of methylene blue onto hazelnut shell: Kinetics, mechanism and activation parameters, J. Hazard. Mater., 164, 172-181.

Dod R., Banerjee G. and Saini S. (2012), Adsorption of Methylene Blue Using Green Pea Peels (Pisum sativum): A Costeffective Option for Dye-Based Wastewater Treatment, Biotechnol. Bioprocess Eng., 17, 862-874.

El Bakouri H., Usero J., Morillo J. and Ouassini A. (2009), Adsorptive features of acid-treated olive stones for drin pesticides: Equilibrium, kinetic and thermodynamic modeling studies, Bioresour. Technol., 100, 4147-4155.

El-Khamsa Guechi and Hamdaoui O. (2013), Cattail leaves as a novel biosorbent for the removal of malachite green from liquid phase: data analysis by non-linear technique, Desalin. Water Treat., 51, 3371-3380.

El-Sayed G.O. (2011), Removal of methylene blue and crystal violet from aqueous solutions by palm kernel fiber, Desalination, 272, 225-232.

Fernandez M.E., Nunell G.V., Bonelli P.R. and Cukierman A.L. (2010), Effectiveness of Cupressus sempervirens cones as biosorbent for the removal of basic dyes from aqueous solutions in batch and dynamic modes, Bioresour. Technol., 101, 9500-9507.

Garg V.K., Amita M., Kumar R. and Gupta R. (2004), Basic dye (methylene blue) removal from simulated wastewater by adsorption using Indian Rosewood sawdust: a timber industry waste, Dyes Pigments, 63, 243-250.

Gupta N., Kushwaha A.K. and Chattopadhyaya M.C. (2012), Adsorption studies of cationic dyes onto Ashoka (Saraca asoca) leaf powder, J Taiwan Inst Chem Eng., 43, 604-613.

Gusmao K.A.G., Gurgel L.V.A, Melo T.M.S. and Gil L.F. (2012), Application of succinylated sugarcane bagasse as adsorbent to remove methylene blue and genetian violet from aqueous solutions - Kinetic and equilibrium studies, Dyes Pigments, 92, 967-974.

Hameed B.H., Mahmoud D.K. and Ahmad A.L. (2008a), Sorption equilibrium and kinetics of basic dye from aqueous solution using banana stalk waste, J.Hazard. Mater., 158, 499-506.

Hameed B.H., Mahmoud D.K. and Ahmad A.L. (2008b), Equilibrium modeling and kinetic studies on the adsorption of basic dye by a low-cost adsorbent: Coconut (Cocos nucifera) bunch waste, J.Hazard. Mater., 158, 65-72.

Hameed B.H. (2009a), Spent tea leaves: A new non-conventional and low-cost adsorbent for removal of basic dye from aqueous solutions, J. Hazard. Mater., 161, 753-759.

Hameed B.H. (2009b), Evaluation of papaya seeds as a novel non-conventional low-cost adsorbent for removal of methylene blue, J.Hazard. Mater., 162, 939-944.

Hameed B.H. and Ahmad A.A. (2009), Batch adsorption of methylene blue from aqueous solution by garlic peel, an agricultural waste biomass, J. Hazard. Mater., 164, 870-875.

Malekbala M.R., Hosseini S., Yazdi S.K., Soltani S.M. and Malekbala M.R. (2012), The study of the potential capability of sugar beet pulp on the removal efficiency of two cationic dyes, Chem.Eng. Rese.Design, 90, 704-712.

Ming-Chen Shih. (2012), Kinetics of the batch adsorption of methylene blue from aqueous solutions onto rice husk: effect of acid modified process and dye concentration, Desalin. Water Treat., 37, 200-214.

Nasuha N., Hameed B.H. and Azam T. Mohd Din (2010), Rejected tea as a potential low-cost adsorbent for the removal of methylene blue, J.Hazard. Mater., 175, 126-132.

Podstawczyk D., Witek - Krowiak A., Chojnacka K. and Sadowski Z. (2014), Biosorption of malachite green by egg shells: Mechanism identification and process optimization, Bioresour. Technol., 160, 161-165. 
Sajab M.S., Chia C.H., Zakaria S., Jani S. M., Ayob M.K., Chee K.L., Khiew P.S. and Chiu W.S. (2011), Citric acid modified kenaf cone fibres for removal of methylene blue from aqueous solution, Bioresour. Technol., 102, 7237-7243.

Sajab M.S., Chia C.H., Zakari S. and Khiew P.S. (2013), Cationic and anionic modifications of oil palm empty fruit bunch fibers for the removal of dyes from aqueous solutions, Bioresour. Technol., 128, 571-577.

Senturk H.B., Ozdes D. and Duran C. (2010), Biosorption of Rhodamine 6G from aqueous solutions onto almond shell (Prunus dulcis) as a low cost adsorbent, Desalination, 252, 81-87.

Song J., Zou W., Bian Y., Su F. and Han R. (2011), Adsorption characteristics of methylene blue by peanut husk in batch and column modes, Desalination, 265, 119-125.

Uddin M.T., Islam M.A., Mahmud S. and Rukanuzzaman M. (2009), Adsorptive removal of methylene blue by tea waste, J.Hazard. Mater., 164, 53-60.

Wang L., Zhang J., Zhao R., Li C., Li Y. and Zhang C. (2010), Adsorption of basic dyes on activated carbon prepared from Polygonum orientale Linn: Equilibrium, kinetic and thermodynamic studies, Desalination, 254, 68-74.

Witek-Krowiak A. (2013), Biosorption of malachite green from aqueous solutions by pine sawdust: equilibrium, kinetics and the effect of process parameters, Desalin. Water Treat., 51, 3284-3294.

Xing Y., Liu D. and Zhang L-P. (2010), Enhanced adsorption of Methylene Blue by EDTAD-modified sugarcane bagasse and photocatalytic regeneration of the adsorbent, Desalination, 259, 187-191.

Yamuna R.T. and Namasivayam C. (1993), Color removal from aqueous solution by biogas residual slurry, Toxicol. Environ. Chem., 38(3-4), 131-143.

Zhang W., Yan H., Li H., Jiang Z., Dong L., Kan X., Yang H., Li A. and Cheng R. (2011), Removal of dyes from aqueous solutions by straw based adsorbents: Batch and column studies, Chem. Eng. J., 168, 1120-1127. 